\title{
Linoleic acid suppresses cholesterol efflux and ATP-binding cassette transporters in murine bone marrow-derived macrophages
}

\author{
Nicole L. Spartano, Stefania Lamon-Fava, Nirupa R. Matthan, Martin S. Obin, Andrew S. \\ Greenberg, and Alice H. Lichtenstein * \\ Jean Mayer USDA Human Nutrition Research Center on Aging at Tufts University, Boston, MA, \\ United States \\ Nicole L. Spartano: nicole.spartano@tufts.edu; Stefania Lamon-Fava: stefania.lamon-fava@tufts.edu; Nirupa R. Matthan: \\ nirupa.matthan@tufts.edu; Martin S. Obin: martin.obin@tufts.edu; Andrew S. Greenberg: andrew.greenberg@tufts.edu
}

\section{Abstract}

Individuals with type 2 diabetes mellitus (T2DM) are at increased risk of developing cardiovascular disease (CVD), possibly associated with elevated plasma free fatty acid concentrations. Paradoxically, evidence suggests that unsaturated, compared to saturated fatty acids, suppress macrophage cholesterol efflux, favoring cholesterol accumulation in the artery wall. Murine bone marrow-derived macrophages (BMDM) were used to further explore the relationship between saturated and unsaturated fatty acids, and cholesterol efflux mediated by ATP-binding cassette transporters (ABCA1 and ABCG1) through transcription factors liver- $\mathrm{x}$ receptor-alpha (LXR-a) and sterol receptor element binding protein (SREBP)-1. BMDM isolated from C57BL/6 mice were exposed to $100 \mathrm{uM}$ linoleic acid (18:2) or palmitic acid (16:0) for $16 \mathrm{hr}$, and $25 \mathrm{ug} / \mathrm{mL}$ oxidized low density lipoprotein for an additional $24 \mathrm{hr}$. ABCA1 and ABCG1 mRNA expression was suppressed to a greater extent by $18: 2$ (60\% and $54 \%$, respectively) than 16:0 (30\% and 29\%, respectively) relative to control (all $p<0.01$ ). 18:2 decreased ABCA1 protein levels by $94 \%$ and high density lipoprotein (HDL) mediated cholesterol efflux by $53 \%$ (both $p<0.05$ ), and had no significant effect on ABCG1, LXR-a or SREBP-1 protein levels. 16:0 had no effect on ABCA1, ABCG1, LXR-a or SREBP-1 protein expression or HDL-mediated cholesterol efflux. These results suggest that 18:2, relative to 16:0, attenuated macrophage HDL-mediated cholesterol efflux through down regulation of ABCA1 mRNA and protein levels but not through changes in LXR-a or SREBP-1 expression. The effect of 18:2 relative to 16:0 on macrophages cholesterol homeostasis may exacerbate the predisposition of individuals with T2DM to increased CVD risk.

*Corresponding Author: Alice H Lichtenstein, D.Sc., Tufts University, Cardiovascular Nutrition Laboratory, J.M. USDA Human Nutrition Research Center on Aging, 711 Washington Street, Boston, MA, USA 02111, Tel.: +1 617556 3127; fax: +1 6175563103. , alice.lichtenstein@tufts.edu.

Other Authors: Tufts University, J.M. USDA Human Nutrition Research Center on Aging, 711 Washington Street, Boston, MA, USA 02111

Conflict of Interest

None declared. 


\section{Keywords}

Bone marrow-derived macrophages; holesterol efflux; ATP-binding cassette transporters; Sterol regulatory element binding protein; Atherosclerosis; Unsaturated fatty acids

\section{Introduction}

Initiation of atherosclerosis lesion formation occurs, in part, through retention of oxidized low density lipoprotein (oxLDL) cholesterol within the artery wall and subsequent macrophage-derived foam cell formation [1]. High density lipoprotein (HDL) particles promote reverse cholesterol transport via their interaction with the macrophage membrane ATP-binding cassette (ABC) transporters and scavenger receptor (SR)-B1 [2]. Two components of this system, HDL concentrations [3,4] and macrophage ABC-transporter expression [5, 6] are low in individuals with type 2 diabetes mellitus (T2DM) [7]. These individuals are at increased risk of developing atherosclerosis.

Among the metabolic disturbances associated with T2DM are chronically elevated free fatty acids (FFA) concentrations [8]. One class of FFA, unsaturated fatty acids, has been reported to suppress expression of the macrophage ABC-transporters ABCA1 and ABCG1, resulting in reduced cholesterol efflux [9-12]. In healthy individuals as well as those with T2DM, linoleic (18:2) and palmitic acid (16:0) are among the highest circulating FFA and therefore were the focus of this study [13]. It has previously been reported that both ABCA1 and ABCG1 protein expression were suppressed by 18:2 in human monocytes-derived macrophages after chemical induction of ABC-transporter expression [12]. ABC-transporter expression and cholesterol efflux are regulated at multiple levels, but the role of FFA exposure has not previously been explored in an oxLDL-loaded primary macrophage model. Stimulation of primary macrophages with oxLDL causes induction of ABC-transporter expression through intracellular cholesteryl ester (CE) accumulation [14], similar to macrophage foam cells found within atherosclerotic plaques. In contrast, it has been reported that chemical induction of $\mathrm{ABC}$-transporter expression does not increase intracellular CE concentration [5], thus differing from macrophage foam cell formation, in vivo. With few exceptions [12], most of the reports available on the relationship between FFA and $\mathrm{ABC}$-transporter expression have been conducted using immortalized macrophage cell lines [9-11]. Such cell lines may not have the same regulation mechanisms for cholesterol transport as primary macrophages, in vivo.

At the post-translational level, 18:2 increases ABCA1 protein turnover via protein kinase $\mathrm{C}$ (PKC)- $\delta$ activation in RAW 264.7 macrophages $[9,10]$. At the transcriptional level, ABCtransporters are regulated by liver-X-receptor (LXR)-a [15, 16]. Polyunsaturated fatty acids (PUFA), such as 18:2 and eicosapentaenoic acid (20:5), and to a lesser extent monounsaturated fatty acids (MUFA), such as oleic acid (18:1), have been reported to disrupt LXR-a activity in transfected RAW 264.7 macrophages [11]. PUFA have also been reported to down regulate transcription of sterol regulatory element binding protein (SREBP)-1c through reduced LXR-a activity [17]. There is a sterol regulatory element (SRE) in the promoter region of the ABCG1 gene [18], suggesting an additional mechanism 
by which unsaturated fatty acids may regulate SREBP-1c activity and subsequent cholesterol efflux. The role of SREBP-2 in ABC-transporter expression is more controversial, with contrasting evidence suggesting that SREBP-2 is either a promoter or repressor of ABCA1 transcription [19, 20].

While there are several mechanisms by which unsaturated fatty acids may cause a suppression of $\mathrm{ABC}$-transporter expression, the complex mechanisms involving transcriptional regulation of cholesterol transporters have not been fully elucidated. The aim of this study was to assess the mechanism by which 18:2, compared to 16:0, disrupts transcriptional regulation of $\mathrm{ABC}$-transporters and cholesterol efflux using bone marrowderived macrophages (BMDM), a primary macrophage cell model. To our knowledge there are no studies to date that have examined the relationship between FFA and ABCtransporter expression in oxLDL-loaded primary macrophage cells, such as BMDM. Previous work has demonstrated that BMDM exhibit the appropriate phenotypic properties necessary to make them a good model for arterial plaque macrophages [21]. The focus of this work was on the role of SREBP-1c in mediating the relationship between fatty acids and macrophage $\mathrm{ABC}$-transporter expression in primary BMDM.

\section{Methods}

\section{Murine-BMDM Cell Culture}

Male C57BL/6 mice (Jackson Laboratories, Bar Harbor, ME) were maintained 2 per cage, 12:12 light:dark cycle, and fed a standard mouse chow diet (Harlan Teklad 7012) in accordance with institutional guidelines. Mice were killed at the age of $10-12$ weeks by $\mathrm{CO}_{2}$ followed by cervical dislocation. Bone marrow cells were isolated from the femurs and tibias by flushing the bone cavity with RPMI medium (Gibco, Life Technologies, Grand Island, NY) as previously described [22]. The harvested cells were washed, plated and differentiated into BMDM with $100 \mathrm{ng} / \mathrm{mL}$ macrophage-colony stimulating factor (eBioscience, San Diego, CA) and grown in medium containing 20\% low endotoxin fetal bovine serum (FBS) (Gibco, Life Technologies) and 1\% penicillin/streptomycin (SigmaAldrich, St. Louis, $\mathrm{MO}$ ) in humidified air at $37^{\circ} \mathrm{C}$ in $5 \% \mathrm{CO}_{2}$. After $4-5$ days, macrophages had adhered to the culture dishes allowing non-adherent cells to be discarded. BMDM differentiation was confirmed by monitoring the expression of the cell surface marker F4/80, preferentially expressed in mature macrophages [22]. Passage of BMDM was achieved by incubation $\left(37^{\circ} \mathrm{C}, 10\right.$ minutes) with $8 \mathrm{mg}$ lidocaine/mL phosphate buffered saline (SigmaAldrich). After passage, cells were pre-treated for 16 hours with 0 or 100 uM 18:2 or 16:0 (Nu-Chek Prep, Elysian, MN) in the presence of $50 \mathrm{uM}$ low endotoxin, fatty acid-free bovine serum albumin (BSA) (Sigma-Aldrich) and 20\% lipoprotein deficient (LD)-FBS. Free fatty acid concentrations in the media were maintained throughout the experiment. Fatty acids:BSA stock solutions (1 mM:0.5 mM) were made up in RPMI [23]. LD-FBS was obtained by ultracentrifugation of FBS at a density of $1.215 \mathrm{~g} / \mathrm{ml}$. Lipid accumulation, mRNA and protein expression were assessed, as described below, after exposure to 25 $\mathrm{ug} / \mathrm{mL}$ oxLDL (Intracel, Frederick, MD) for 24 hours. 


\section{Quantitative real-time PCR}

RNA was extracted from BMDM using TRIzol reagent (Ambion, Life Technologies) and Rneasy mini kit (Qiagen, Valencia, CA). Reverse transcription was performed using the Reverse Transcription Kit (Promega, Madison, WI). Real Time PCR was performed using Qiagen's Quantitect primer assays for murine ABCA1, ABCG1, SR-B1, LXR-a and beta ( $\beta$ )-actin (QT00165690, QT00113519, QT00166495, QT00113729, QT01136772). Additionally, primers were designed for the following genes (Table 1): SREBP-1a, -1c, -2, acetyl CoA carboxylase (ACC), and stearoyl CoA desaturase 1 (SCD1). All templates were initially denatured for 5 minutes at $95^{\circ} \mathrm{C}$, followed by a standard thermal cycle (repeated 40 times): denaturation at $94^{\circ} \mathrm{C}$ for $1 \mathrm{~min}$, annealing at $55^{\circ} \mathrm{C}$ for $30 \mathrm{sec}$, and extension at $72^{\circ} \mathrm{C}$ for $34 \mathrm{sec}$. Relative quantification $(\Delta \Delta \mathrm{Ct})$ was used to assess expression of target genes and standardized to the internal reference gene, $\beta$-actin.

\section{Western blot analysis}

BMDM were lysed in RIPA buffer (Sigma-Aldrich) containing protease inhibitors (Bio-Rad, Hercules, CA) for whole cell protein extraction. Nuclear protein extraction was performed as previously described [24]. Briefly, cells were resuspended in a fractionation buffer containing protease inhibitors (Bio-Rad), passed through a 22.5 gauge needle 30 times, and centrifuged at $1000 \times \mathrm{g}$ for $7 \mathrm{~min}$ at $4^{\circ} \mathrm{C}$. The pellet was resuspended in another fractionation buffer containing protease inhibitors (Bio-Rad), rotated at $4^{\circ} \mathrm{C}$ for $1 \mathrm{hr}$, and centrifuged at $100,000 \times \mathrm{g}$ for $30 \mathrm{~min}$ at $4^{\circ} \mathrm{C}$ in a Beckman TLA 100.2 rotor. The supernatant from this spin was designated the nuclear extract.

Whole cell and nuclear protein concentrations were determined by MicroBCA protein assay (Bio-Rad). Proteins were separated by SDS-PAGE (Bio-Rad) under reducing conditions and transferred to nitrocellulose membranes (Bio-Rad). Quantification by Western blotting was performed using the following primary antibodies: ABCA1 (Abcam, Cambridge, MA), ABCG1 (Santa Cruz Biotechnology, Santa Cruz, CA), SR-B1 (Santa Cruz), LXR-a (Abcam), SREBP-1 (Abcam), and $\beta$-actin (Sigma-Aldrich). Secondary antibodies were purchased from Santa Cruz Biotechnology. Signals were visualized by chemiluminescence (Amersham Biosciences, Piscataway, NJ) and quantified using a GS-800 calibrated densitometer (Bio-Rad).

\section{Assessment of BMDM lipid composition}

After lipid extraction [25] cellular triacylglycerol (TAG) content was determined using a colorimetric enzyme-linked kit (Sigma-Aldrich). Cellular total cholesterol (TC) and free cholesterol (FC) content were determined by gas chromatography using 5-a cholestane as an internal standard as previously described [26]. CE was calculated as the difference between TC and FC. Cellular FC, TC, CE and TAG were expressed as ug/mg cellular protein.

\section{Cholesterol efflux assay}

BMDM were pre-incubated with $1 \mathrm{uCi} / \mathrm{ml}\left[{ }^{3} \mathrm{H}\right]$ cholesterol (Perkin Elmer, Waltham, MA) and $25 \mathrm{ug} / \mathrm{mL}$ oxLDL for 24 hours [10, 27]. Immediately thereafter the cells were equilibrated in RPMI containing $2 \mathrm{mg} / \mathrm{mL}$ fatty acid-free BSA for 6 hours. BMDM were 
then incubated with $50 \mathrm{ug} / \mathrm{mL}$ HDL (Intracel) in serum-free media for 4 hours [27]. FFA concentrations in the media were maintained constant throughout the entire experiment. Fraction cholesterol efflux was estimated from the ratio of the radiotracer in the medium to the total (medium + cells) and normalized for cellular protein.

\section{Statistical analysis}

All data are reported as mean \pm standard deviation (SD). Student's t-test was used to test significant differences between two treatments and analysis of variance (ANOVA) was used to test for significant differences among three treatments, followed by Tukey's test (SAS version 9.3, SAS Institute Inc, Cary, NC). A $p$-value < 0.05 was considered significant for all tests.

\section{Results}

\section{No additional effect of $18: 2$ or 16:0 on CE accumulation after exposure to oxLDL}

To characterize the model of oxLDL-stimulated BMDM, the effects of oxLDL on lipid accumulation was examined. After 24 hours of exposure to oxLDL, CE concentrations increased from undetectable levels to approximately $30 \mathrm{ug} \mathrm{CE} / \mathrm{mg}$ protein (Fig. 1A, $p<0.0001)$ without significant effects on FC and TAG concentrations. In a separate set of

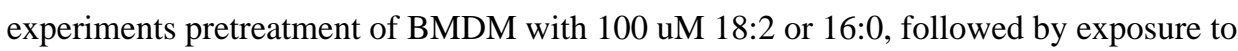
oxLDL, had no additional effects on lipid accumulation (Fig. 1B). From these data we concluded that, in the presence of oxLDL, exposure to 18:2 or 16:0 did not alter BMDM lipid accumulation.

\section{8:2 suppresses HDL-mediated cholesterol efflux}

The effect of pre-treating BMDM with 18:2 and 16:0 on cholesterol efflux was next

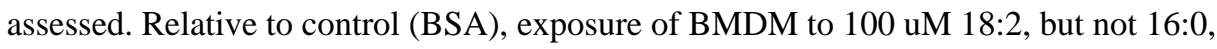
resulted in 53\% lower cholesterol efflux (Fig. 2, $p<0.05$ ). On the basis of these data cholesterol transporter expression was next assessed.

\section{8:2 decreases ABCA1 mRNA and protein expression}

Pre-treating BMDM with 18:2 and 16:0 and then exposing the cells to oxLDL decreased ABCA1 mRNA expression by $60 \%(p<0.001)$ and $30 \%(p<0.01)$, respectively, and ABCG1 mRNA expression by 54\% $(p<0.0001)$ and $29 \%(p<0.01)$, respectively, compared to BSA + oxLDL treated cells (Fig. 3A). In contrast, 18:2, but not 16:0, suppressed SR-B1 mRNA expression by $21 \%$ (Fig. $3 \mathrm{~A}, p<0.05$ ). ABCA1 protein expression was reduced by $93 \%$ with 18:2 treatment only (Fig. 3B, $p<0.05$ ), but there was no significant effect of either fatty acid on ABCG1 and SR-B1 protein expression or LXR-a mRNA or protein expression (Fig. 3B). On the basis of these data, we further examined the effect of 16:0 and 18:2 on the transcription factor SREBP-1c. It has been suggested that SREBP-1c is involved in the regulation of $\mathrm{ABC}$-transporters at the transcriptional level [18, 28]. 


\section{8:2 decreases SREBP-1 mRNA, but not SREBP-1 nuclear protein expression}

In oxLDL-stimulated BMDM, treatment with 18:2, but not 16:0, suppressed SREBP-1c mRNA expression by $97 \%$ ( $p<0.0001)$, consistent with suppression of mRNA expression of its target genes, SCD1 by $97 \%(p<0.001)$ and ACC by $48 \%(p<0.05)$, (Fig. 4A). Likewise, treatment with 18:2, but not 16:0, suppressed expression of SREBP-1a mRNA by $28 \%$ $(\mathrm{p}<0.05)$. There was no significant effect of 16:0 or 18:2 on SREBP-1 nuclear protein expression (Fig. 4B and C), despite changes in mRNA expression. These data suggest that the change in SREBP-1 mRNA expression did not play a major role in the effect of 18:2 or 16:0 on ABC-transporter expression.

\section{Discussion}

Diet, lifestyle, and certain disease states alter total circulating FFA concentrations [13]. For example, individuals with T2DM tend to have twice the plasma FFA concentration of individuals without T2DM, and likewise have two-fold higher plasma 18:2 concentrations. In the current study, we found that 18:2, but not 16:0, caused a marked suppression of cholesterol efflux from BMDM after exposure to an acceptor, HDL. The cause of this suppression may occur at multiple levels of cellular regulation. The data suggest the mechanisms are not mediated by differences in cellular cholesterol accumulation. In our model, oxLDL-loaded BMDM, exposure to 18:2 led to a suppression in ABC-transporter gene expression as well as ABCA1 protein expression. These changes likely contributed to the corresponding suppression of cholesterol efflux.

Studies implicating activation of PKC- $\delta$ and impairment of LXR- $a$ activity as the mechanisms responsible for $\mathrm{ABC}$-transporter suppression in response to unsaturated fatty acids have been reported in immortalized cell lines [9-11]. However, the translation of results from immortalized cell lines to the in vivo state must be done cautiously. For example, THP-1 macrophages differ from primary human macrophages in LXR-a activation in response to stimuli [29]. Mechanistic work to identify the role transcriptional regulation has on ABC-transporters has not previously been reported in primary macrophage models. Therefore, the use of an ex vivo primary macrophage model, BMDM, was chosen to further explore this issue.

While LXR-a directly affects ABC-transporter expression, it also influences SREBP-1c mRNA expression [17]. Previous research suggests that PUFA disrupts LXR- $\alpha$ activity on the SREBP-1c promoter, leading to a strong suppression of SREBP-1c mRNA expression [17]. Data from the current study are consistent with this observation. Our findings suggest that neither 18:2 nor 16:0 had a significant effect on LXR-a expression, although variation in individual experimental results precludes our ability to draw a definitive conclusion about the effect of FFA on LXR-a expression. We are also unable to rule out the possibility that these fatty acids affected LXR-a activity, as indicated in previous studies [11].

SREBP-1c is predicted to have a binding site in the ABCG1 promoter region [18]. On this basis we hypothesized that SREBP-1c suppression would mediate the effect of 18:2 on ABC-transporter expression. However, we found that although SREBP-1c and 1a mRNA expression were reduced by 18:2, SREBP-1 nuclear protein expression was unaffected. Our 
results differ from previous studies which reported that nuclear maturation of SREBP-1 is lower in response to unsaturated than saturated fatty acids [17]. Our findings likely differ from prior work because, in addition to the fatty acid exposure period, exogenous cholesterol was added in the form of oxLDL. In vivo, oxLDL is a key initiating element in the transformation of macrophages to foam cells, which was the focus of the current work. The possibility cannot be ruled out that intracellular cholesterol accumulation stimulated by addition of oxLDL may have overridden the effect of 18:2 on SREBP-1 nuclear protein. SREBP-1 subcellular localization is tightly regulated by SREBP cleavage-activating protein, which is activated by cellular cholesterol [30]. This strict post-translational regulation of SREBP-1 may explain the stability of nuclear SREBP-1 protein expression levels, even with large changes in SREBP-1 mRNA expression. We are also unable to determine whether 18:2 had a direct effect on ABC-transporter expression through alteration of SREBP-1 binding to promoter regions.

Evidence from previous studies suggests that the suppressive effect of 18:2 on cholesterol efflux is mediated at the transcriptional and post-translational levels [9-11]. At the transcriptional level, ABC-transporter expression is stimulated by the binding of oxysterols, derivatives of cholesterol which are abundant in cholesterol-loaded cells, to the transcription factor LXR-a. Binding of oxysterols to LXR-a causes a conformational change which enables LXR-a to bind to promoter region in ABC-transporter genes [11]. 18:2 has been reported to disrupt LXR-a activity by binding to response elements in ABCA1 or ABCG1 promoters, thus reducing transcription of $\mathrm{ABC}$-transporters [11]. At the post-translational level, 18:2 has been shown to induce ABCA1 phosphorylation and protein turnover through a pathway involving PKC- $\delta[9,10]$. Absence of an effect of 18:2 on ABCG1 protein expression, in light of suppression of ABCG1 mRNA expression, suggests tight translational or post-translational regulation over ABCG1 protein expression. These mechanisms were not explored in the current study, but may play a role in our observed results.

Results from our study agree with previous studies that suggest that 18:2 suppresses macrophage HDL-mediated cholesterol efflux through down regulation of ABC-transporter expression, but this study does not support the conclusion that a mechanism involving SREBP-1 plays a role in this response. The effect of 18:2 on macrophage cholesterol efflux may be partially responsible for the increased risk of CVD in individuals with T2DM, associated with elevated circulating FFA concentrations.

\section{Acknowledgments}

The authors would like to thank Dr. Donald Smith and staff from the Comparative Biology Unit at the Jean Mayer USDA Human Nutrition Research Center on Aging (Tufts University, Boston) for assistance with animal care and feeding.

\section{Sources of funding}

This work was supported by grants from the NIH: NHLBI-T32-HL069772 (NLS) and the USDA agreement No. 58-1950-0-0014. Any opinions, findings, conclusion, or recommendations expressed in this publication are those of the author(s) and do not necessarily reflect the view of the U.S. Department of Agriculture. 


\section{Abbreviations}

$\begin{array}{ll}\text { ABC } & \text { ATP-binding cassette } \\ \text { ACC } & \text { Acetyl CoA carboxylase } \\ \text { ANOVA } & \text { Analysis of variance } \\ \text { BMDM } & \text { Bone marrow-derived macrophages } \\ \text { BSA } & \text { Bovine serum albumin } \\ \text { CE } & \text { Cholesteryl ester } \\ \text { CVD } & \text { Cardiovascular disease } \\ \text { FBS } & \text { Fetal bovine serum } \\ \text { FC } & \text { Free cholesterol } \\ \text { FFA } & \text { Free fatty acids } \\ \text { HDL } & \text { High density lipoprotein } \\ \text { LD } & \text { Lipoprotein deficient } \\ \text { LXR-a } & \text { Liver-x-receptor-alpha } \\ \text { MUFA } & \text { Monounsaturated fatty acids } \\ \text { OXLDL } & \text { Oxidized low density lipoprotein } \\ \text { PKC } & \text { Protein kinase C } \\ \text { PUFA } & \text { Polyunsaturated fatty acids } \\ \text { SCD } & \text { Stearoyl CoA desaturase } \\ \text { SD } & \text { Standard deviation } \\ \text { SR } & \text { Scavenger receptor } \\ \text { SRE } & \text { Sterol regulatory element } \\ \text { SREBP } & \text { Sterol receptor element binding protein } \\ \text { T2DM } & \text { Type 2 diabetes mellitus } \\ \text { TC } & \text { Total cholesterol } \\ \text { TAG } & \text { Triacylglycerol } \\ & \end{array}$

\section{References}

1. Kaplan M, Aviram M, Hayek T. Oxidative stress and macrophage foam cell formation during diabetes mellitus-induced atherogenesis: role of insulin therapy. Pharmacol Ther. 2012; 136:175185. [PubMed: 22890211]

2. Ohashi R, Mu H, Wang X, Yao Q, Chen C. Reverse cholesterol transport and cholesterol efflux in atherosclerosis. QJM : monthly journal of the Association of Physicians. 2005; 98:845-856. [PubMed: 16258026]

3. National Cholesterol Education Program (NCEP) Expert Panel on Detection, Evaluation and Treatment of High Blood Cholesterol in Adults (Adult Treatment Panel III). Third Report of the 
National Cholesterol Education Program (NCEP) Expert Panel on Detection, Evaluation, and Treatment of High Blood Cholesterol in Adults (Adult Treatment Panel III) final report. Circulation. 2002; 106:3143-3421. [PubMed: 12485966]

4. Assmann G, Schulte H, von Eckardstein A, Huang Y. High-density lipoprotein cholesterol as a predictor of coronary heart disease risk. The PROCAM experience and pathophysiological implications for reverse cholesterol transport. Atherosclerosis. 1996; 124:S11-S20. [PubMed: 8831911]

5. Mauldin JP, Nagelin MH, Wojcik AJ, Srinivasan S, Skaflen MD, Ayers CR, McNamara CA, Hedrick CC. Reduced expression of ATP-binding cassette transporter G1 increases cholesterol accumulation in macrophages of patients with type 2 diabetes mellitus. Circulation. 2008; 117:2785-2792. [PubMed: 18490524]

6. Zhou H, Tan KC, Shiu SW, Wong Y. Determinants of leukocyte adenosine triphosphate-binding cassette transporter G1 gene expression in type 2 diabetes mellitus. Metabolism. 2008; 57:11351140. [PubMed: 18640393]

7. Ryden L, Standl E, Bartnik M, Van den Berghe G, Betteridge J, de Boer MJ, Cosentino F, Jonsson B, Laakso M, Malmberg K, Priori S, Ostergren J, Tuomilehto J, Thrainsdottir I, Vanhorebeek I, Stramba-Badiale M, Lindgren P, Qiao Q, Priori SG, Blanc JJ, Budaj A, Camm J, Dean V, Deckers J, Dickstein K, Lekakis J, McGregor K, Metra M, Morais J, Osterspey A, Tamargo J, Zamorano JL, Deckers JW, Bertrand M, Charbonnel B, Erdmann E, Ferrannini E, Flyvbjerg A, Gohlke H, Juanatey JR, Graham I, Monteiro PF, Parhofer K, Pyorala K, Raz I, Schernthaner G, Volpe M, Wood D. Guidelines on diabetes, pre-diabetes, and cardiovascular diseases: executive summary. The Task Force on Diabetes and Cardiovascular Diseases of the European Society of Cardiology (ESC) and of the European Association for the Study of Diabetes (EASD). Eur Heart J. 2007; 28:88-136. [PubMed: 17220161]

8. Garvey WT, Kwon S, Zheng D, Shaughnessy S, Wallace P, Hutto A, Pugh K, Jenkins AJ, Klein RL, Liao Y. Effects of insulin resistance and type 2 diabetes on lipoprotein subclass particle size and concentration determined by nuclear magnetic resonance. Diabetes. 2003; 52:453-462. [PubMed: 12540621]

9. Wang Y, Oram JF. Unsaturated fatty acids phosphorylate and destabilize ABCA1 through a phospholipase D2 pathway. J Biol Chem. 2005; 280:35896-35903. [PubMed: 16118212]

10. Wang Y, Oram JF. Unsaturated fatty acids phosphorylate and destabilize ABCA1 through a protein kinase C delta pathway. J Lipid Res. 2007; 48:1062-1068. [PubMed: 17325386]

11. Uehara Y, Miura S, von Eckardstein A, Abe S, Fujii A, Matsuo Y, Rust S, Lorkowski S, Assmann G, Yamada T, Saku K. Unsaturated fatty acids suppress the expression of the ATP-binding cassette transporter G1 (ABCG1) and ABCA1 genes via an LXR/RXR responsive element. Atherosclerosis. 2007; 191:11-21. [PubMed: 16730733]

12. Mauerer R, Ebert S, Langmann T. .High glucose, unsaturated and saturated fatty acids differentially regulate expression of ATP-binding cassette transporters ABCA1 and ABCG1 in human macrophages. Exp Mol Med. 2009; 41:126-132. [PubMed: 19287193]

13. Liu L, Li Y, Guan C, Li K, Wang C, Feng R, Sun C. Free fatty acid metabolic profile and biomarkers of isolated post-challenge diabetes and type 2 diabetes mellitus based on GC-MS and multivariate statistical analysis. J Chromatogr B Analyt Technol Biomed Life Sci. 2010; 878:2817-2825.

14. Bostrom P, Magnusson B, Svensson PA, Wiklund O, Boren J, Carlsson LM, Stahlman M, Olofsson SO, Hulten LM. Hypoxia converts human macrophages into triglyceride-loaded foam cells. Arterioscler Thromb Vasc Biol. 2006; 26:1871-1876. [PubMed: 16741148]

15. Jessup W, Gelissen IC, Gaus K, Kritharides L. Roles of ATP binding cassette transporters A1 and G1, scavenger receptor BI and membrane lipid domains in cholesterol export from macrophages. Curr Opin Lipidol. 2006; 17:247-257. [PubMed: 16680029]

16. Wang X, Rader DJ. Molecular regulation of macrophage reverse cholesterol transport. Current opinion in cardiology. 2007; 22:368-372. [PubMed: 17556891]

17. Yoshikawa T, Shimano H, Yahagi N, Ide T, Amemiya-Kudo M, Matsuzaka T, Nakakuki M, Tomita S, Okazaki H, Tamura Y, Iizuka Y, Ohashi K, Takahashi A, Sone H, Osuga JiJ, Gotoda T, Ishibashi S, Yamada N. Polyunsaturated fatty acids suppress sterol regulatory element-binding 
protein 1c promoter activity by inhibition of liver X receptor (LXR) binding to LXR response elements. J Biol Chem. 2002; 277:1705-1711. [PubMed: 11694526]

18. Langmann T, Porsch-Ozcurumez M, Unkelbach U, Klucken J, Schmitz G. Genomic organization and characterization of the promoter of the human ATP-binding cassette transporter-G1 (ABCG1) gene. Biochim Biophys Acta. 2000; 1494:175-180. [PubMed: 11072082]

19. Wong J, Quinn CM, Brown AJ. SREBP-2 positively regulates transcription of the cholesterol efflux gene, ABCA1, by generating oxysterol ligands for LXR. Biochem J. 2006; 400:485-491. [PubMed: 16901265]

20. Zeng L, Liao H, Liu Y, Lee TS, Zhu M, Wang X, Stemerman MB, Zhu Y, Shyy JY. Sterolresponsive element-binding protein (SREBP) 2 down-regulates ATP-binding cassette transporter A1 in vascular endothelial cells: a novel role of SREBP in regulating cholesterol metabolism. $\mathrm{J}$ Biol Chem. 2004; 279:48801-48807. [PubMed: 15358760]

21. Francke A, Herold J, Weinert S, Strasser RH, Braun-Dullaeus RC. Generation of mature murine monocytes from heterogeneous bone marrow and description of their properties. J Histochem Cytochem. 2011; 59:813-825. [PubMed: 21705645]

22. Nguyen MT, Favelyukis S, Nguyen AK, Reichart D, Scott PA, Jenn A, Liu-Bryan R, Glass CK, Neels JG, Olefsky JM. A subpopulation of macrophages infiltrates hypertrophic adipose tissue and is activated by free fatty acids via Toll-like receptors 2 and 4 and JNK-dependent pathways. J Biol Chem. 2007; 282:35279-35292. [PubMed: 17916553]

23. Dillard A, Matthan NR, Lichtenstein AH. Tamm-Horsfall protein 1 macrophage lipid accumulation unaffected by fatty acid double-bond geometric or positional configuration. Nutr Res. 2011; 31:625-630. [PubMed: 21925348]

24. DeBose-Boyd RA, Brown MS, Li WP, Nohturfft A, Goldstein JL, Espenshade PJ. Transportdependent proteolysis of SREBP: relocation of site-1 protease from Golgi to ER obviates the need for SREBP transport to Golgi. Cell. 1999; 99:703-712. [PubMed: 10619424]

25. Schwartz DM, Wolins NE. A simple and rapid method to assay triacylglycerol in cells and tissues. J Lipid Res. 2007; 48:2514-2520. [PubMed: 17717377]

26. Matthan NR, Giovanni A, Schaefer EJ, Brown BG, Lichtenstein AH. Impact of simvastatin, niacin, and/or antioxidants on cholesterol metabolism in CAD patients with low HDL. J Lipid Res. 2003; 44:800-806. [PubMed: 12562840]

27. Meyer JM, Ji A, Cai L, van der Westhuyzen DR. High-capacity selective uptake of cholesteryl ester from native LDL during macrophage foam cell formation. J Lipid Res. 2012; 53:2081-2091. [PubMed: 22833685]

28. Ecker J, Langmann T, Moehle C, Schmitz G. Isomer specific effects of Conjugated Linoleic Acid on macrophage ABCG1 transcription by a SREBP-1c dependent mechanism. Biochem Biophys Res Commun. 2007; 352:805-811. [PubMed: 17141191]

29. Kohro T, Tanaka T, Murakami T, Wada Y, Aburatani H, Hamakubo T, Kodama T. A comparison of differences in the gene expression profiles of phorbol 12-myristate 13-acetate differentiated THP-1 cells and human monocyte-derived macrophage. J Atheroscler Thromb. 2004; 11:88-97. [PubMed: 15153668]

30. Nohturfft A, Yabe D, Goldstein JL, Brown MS, Espenshade PJ. Regulated step in cholesterol feedback localized to budding of SCAP from ER membranes. Cell. 2000; 102:315-323. [PubMed: 10975522]

31. Kakuma T, Lee Y, Higa M, Wang Z, Pan W, Shimomura I, Unger RH. Leptin, troglitazone, and the expression of sterol regulatory element binding proteins in liver and pancreatic islets. Proc Natl Acad Sci U S A. 2000; 97:8536-8541. [PubMed: 10900012]

32. Yecies JL, Zhang HH, Menon S, Liu S, Yecies D, Lipovsky AI, Gorgun C, Kwiatkowski DJ, Hotamisligil GS, Lee CH, Manning BD. Akt stimulates hepatic SREBP1c and lipogenesis through parallel mTORC1-dependent and independent pathways. Cell Metab. 2011; 14:21-32. [PubMed: 21723501] 
A

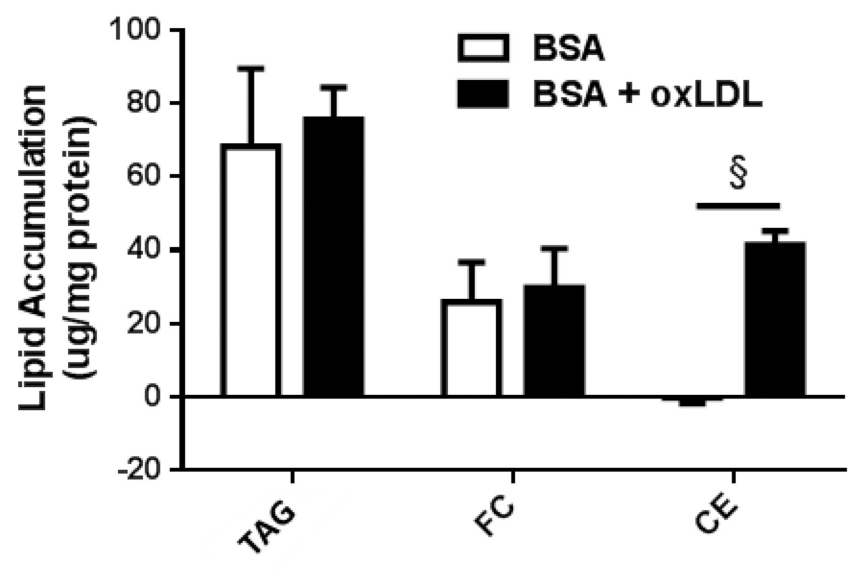

B

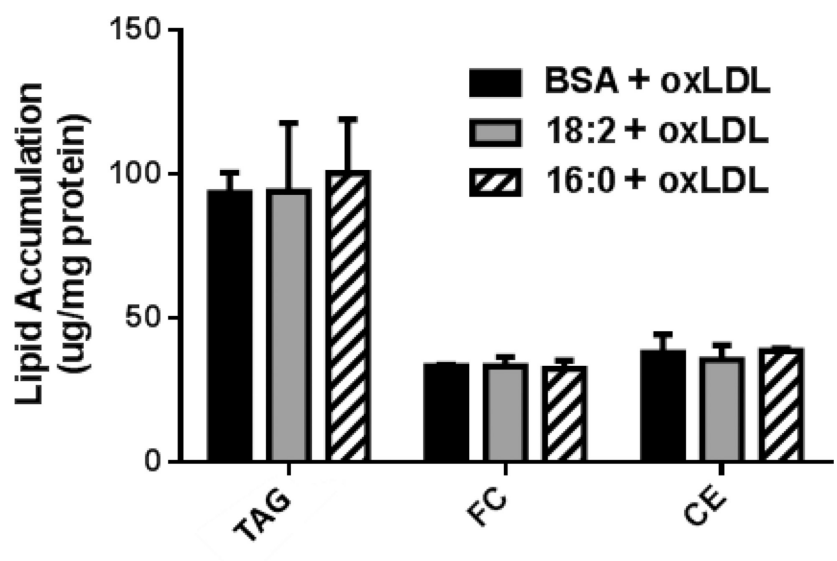

Fig. 1.

Effect of (A) oxLDL (B) oxLDL +/- FFA on lipid accumulation in BMDM. Lipids were first extracted from cells. Triacylglycerol (TAG) was determined using a colorimetric TAG Accumulation Kit and total and free cholesterol (TC and FC) were determined by gas chromatography, cholesteryl esters (CE) was determined by the difference between TC and FC. Values are representative of 3 independent experiments performed in triplicate. $\S p<0.0001$ for the comparison of BSA versus BSA + oxLDL. 


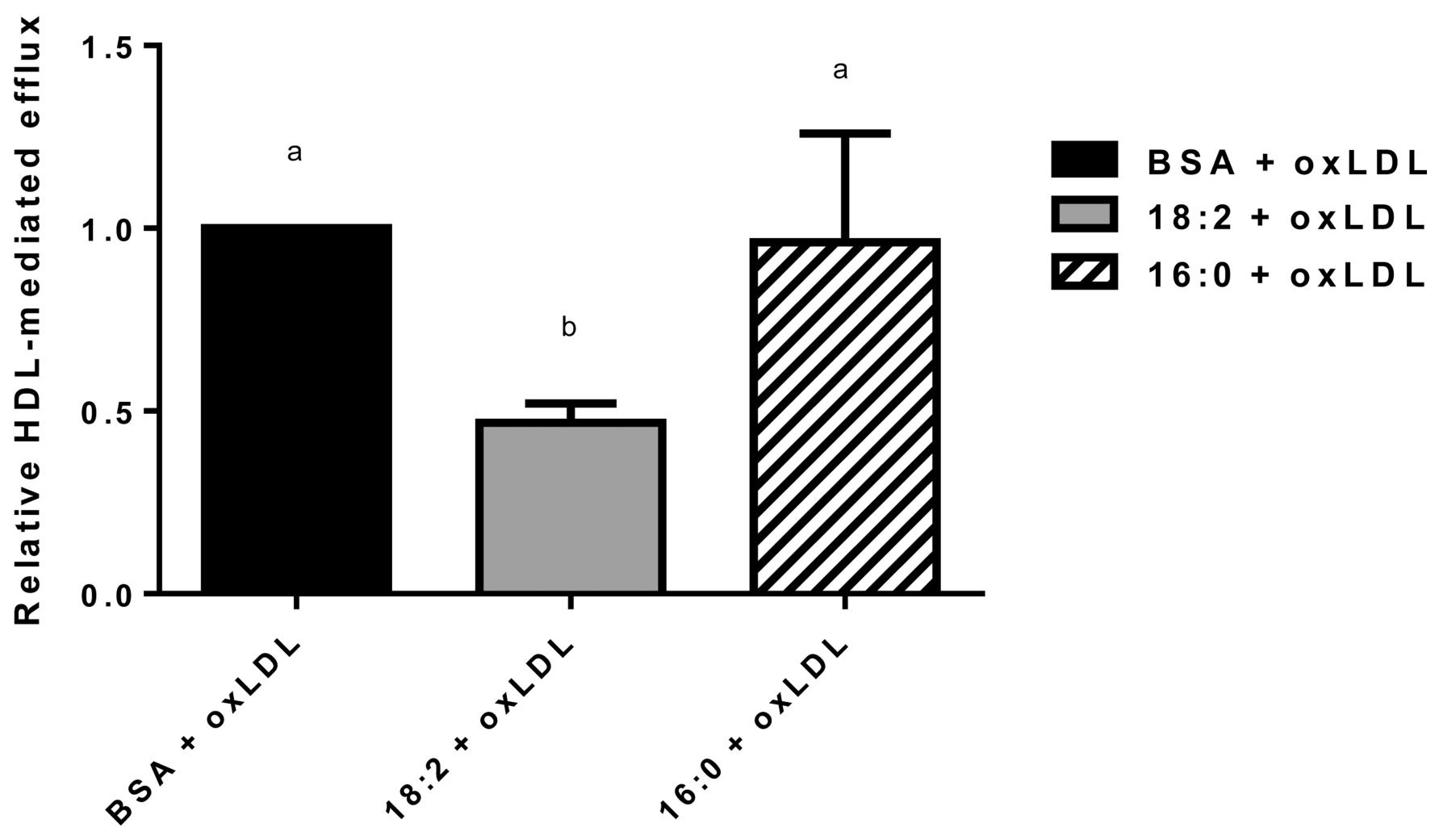

Fig. 2.

Effect of 18:2 and 16:0 on cholesterol efflux in BMDM. OxLDL- and [ ${ }^{3} \mathrm{H}$ ] cholesterol-loaded BMDM were stimulated with 50 ug/mL HDL for 4 hours. Fraction cholesterol efflux was estimated from the ratio of the radiotracer in the medium to the total (medium + cells) and normalized for cellular protein. Values are representative of 3 independent experiments in triplicate. Bars without a common letter are significantly different $(p<0.05)$. 
A

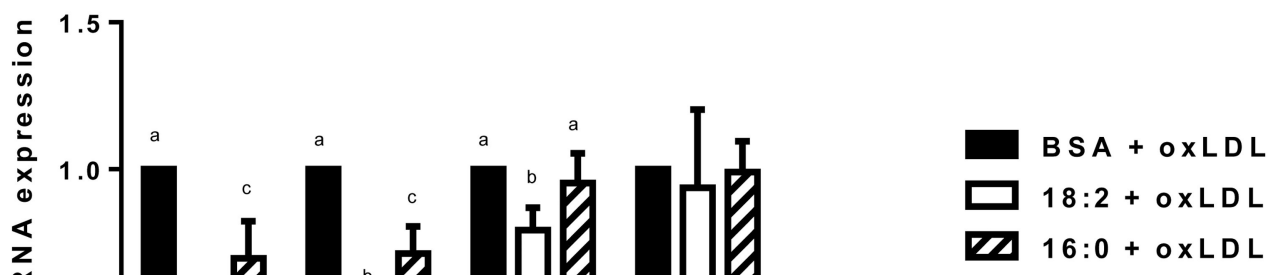

B
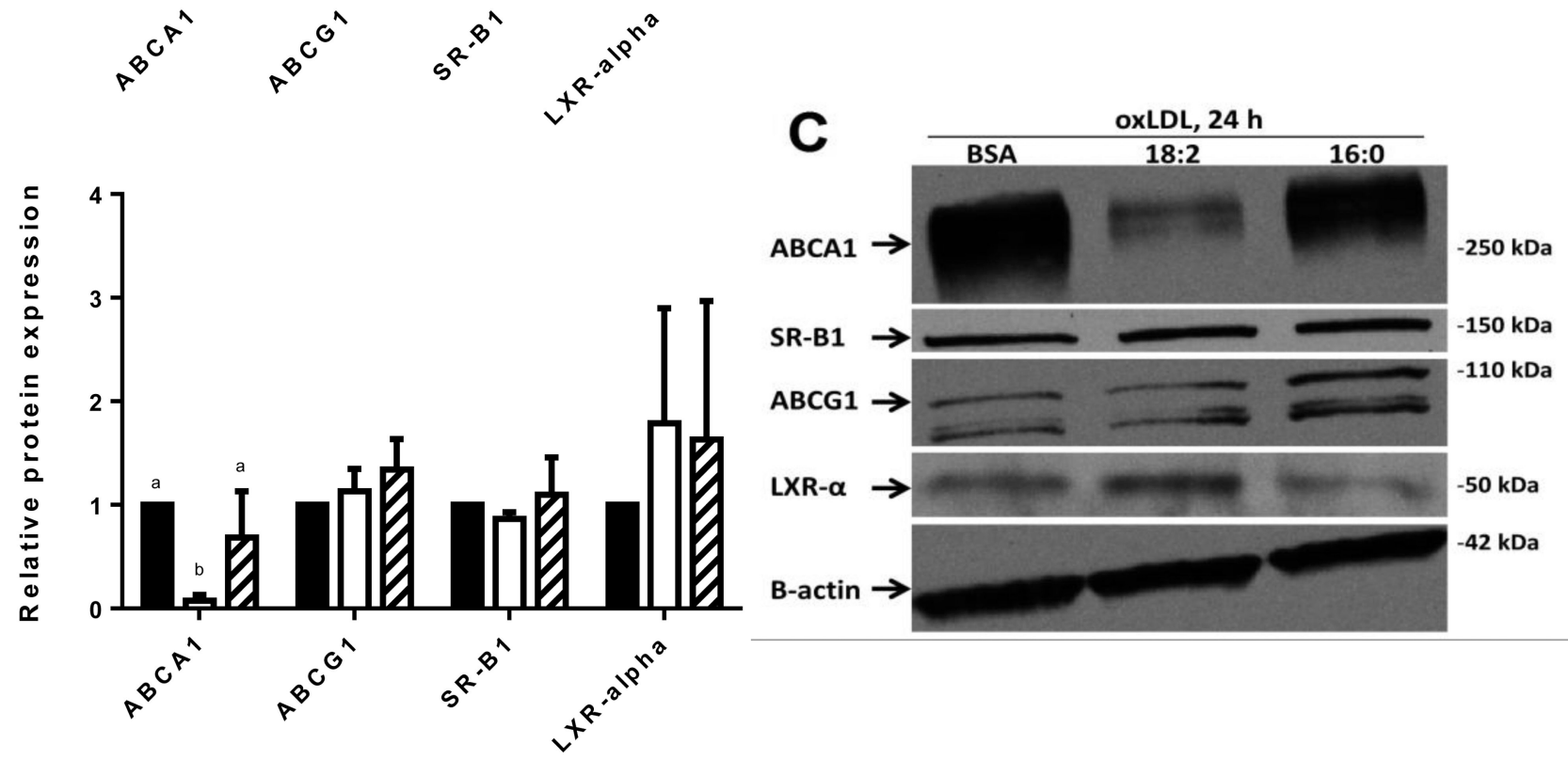

Fig. 3.

Effect of 18:2 and 16:0 on ABCA1, ABCG1, SR-B1 and LXR-a mRNA and protein expression in BMDM. (A) ABCA1, ABCG1, SR-B1 and LXR-a mRNA expression was determined by real-time PCR. $\beta$-actin was used as a standard housekeeping gene. (B) ABCA1, ABCG1, SR-B1, LXR- $\alpha$ and $\beta$-actin protein expression was determined by Western blotting of BMDM cell lysates. $\beta$-actin was used to control equal loading. (C) Representative Western blot. Values are the mean $+/-$ SD 3 independent experiments performed in triplicate. Bars without a common letter are significantly different $(p<0.05)$. 
A

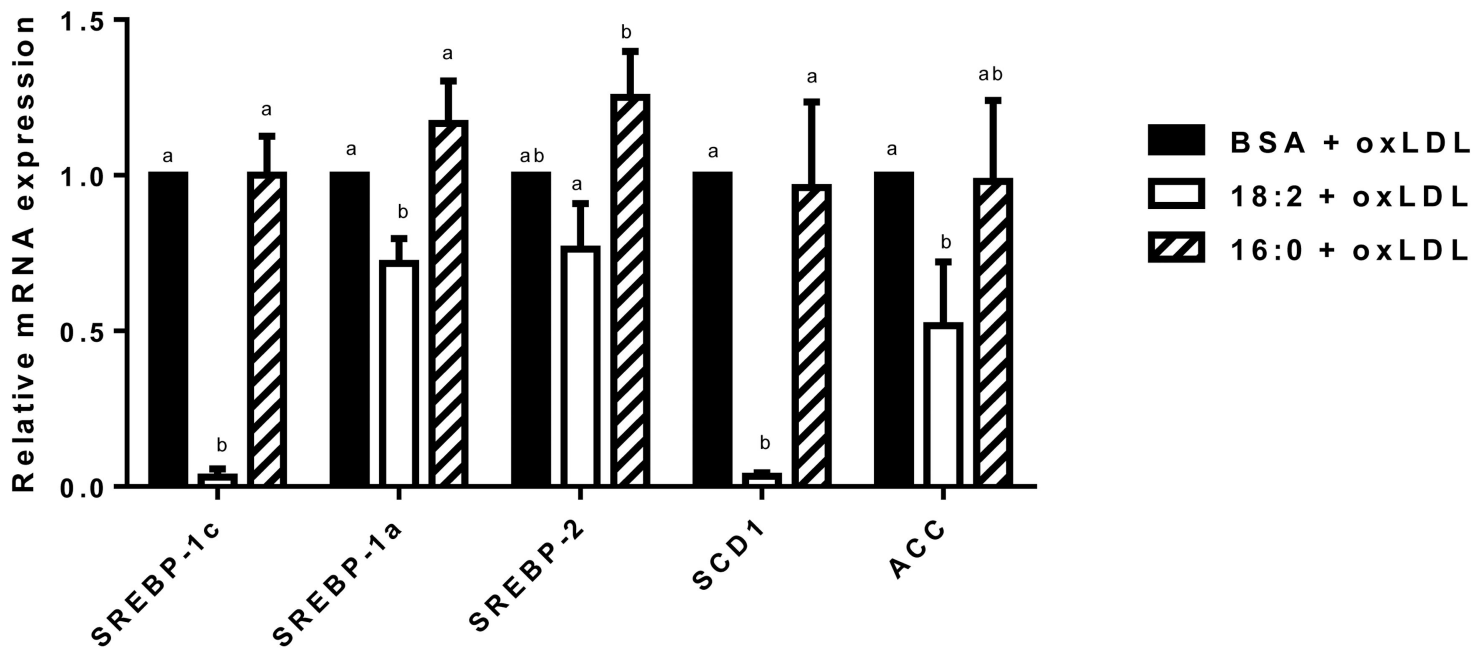

B

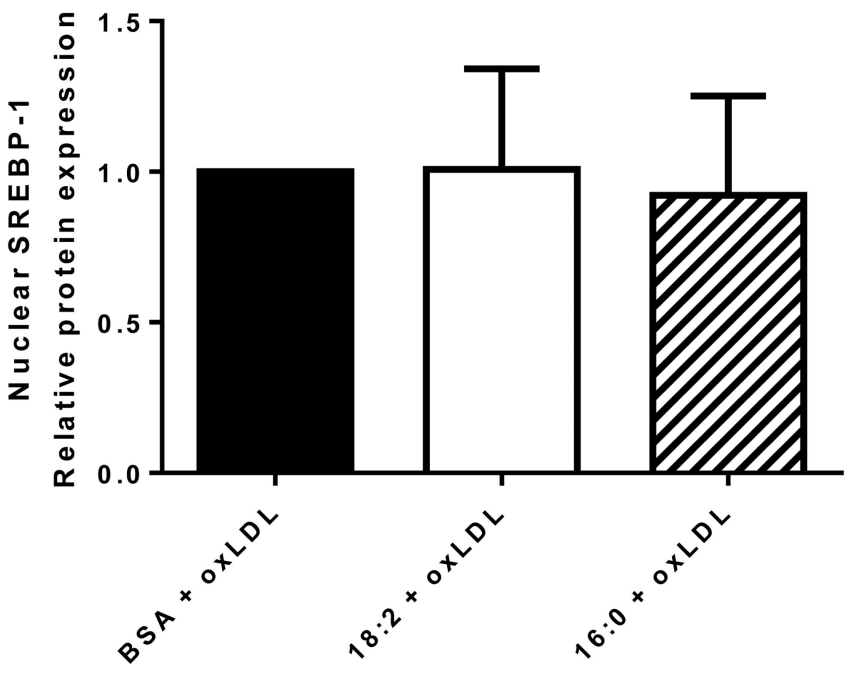

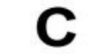

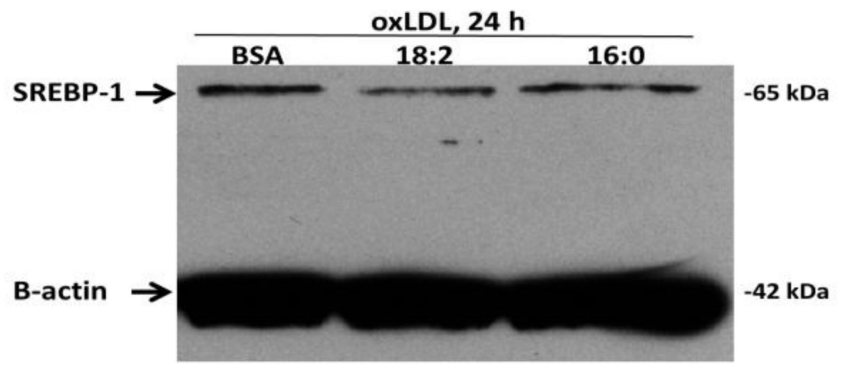

Fig. 4.

Effect of 18:2 and 16:0 on SREBP-1a, 1c, 2, SCD1, and ACC mRNA and SREBP-1 nuclear protein expression in BMDM. (A)

SREBP-1a, 1c, 2, SCD1, and ACC mRNA expression was determined by real-time PCR. $\beta$-actin was used as a standard housekeeping gene. (B) SREBP-1 nuclear protein expression was determined by Western blotting of BMDM nuclear extracts. $\beta$-actin was used to control equal loading. (C) Representative Western blot. Values represent the mean $+/-$ SD of 3 independent experiments performed in triplicate. Bars without a common letter are significantly different $(p<0.05)$. 
Table 1

Real Time PCR primer sequences for SREBP-1a, 1c, 2, SCD1 and ACC

\begin{tabular}{|c|c|c|}
\hline Gene & Primer sequence & Reference \\
\hline SREBP-1a & $\begin{array}{r}\text { F 5'-ACACAGCGGTTTTGAACGACATC-3' } \\
\text { R 5'-ACGGACGGGTACATCTTTACAG-3' }\end{array}$ & {$[31]$} \\
\hline SREBP-1c & $\begin{array}{r}\text { F 5'-GGAGCCATGGATTGCACATT-3' } \\
\text { R 5'-ACGGACGGGTACATCTTTAC-3' }\end{array}$ & Adapted from [31] \\
\hline SREBP-2 & $\begin{array}{r}\text { F 5'-CACAATATCATTGAAAAGCGCTACC-3' } \\
\text { R 5'-TTTTTCTGATTGGCCAGCTTCAGCA-3' }\end{array}$ & {$[31]$} \\
\hline SCD1 & $\begin{array}{r}\text { F 5'-CTGACCTGAAAGCCGAGAAG-3' } \\
\text { R 5'-GCGTTGAGCACCAGAGTGTA-3' }\end{array}$ & {$[32]$} \\
\hline ACC & $\begin{array}{r}\text { F 5'-ACAGTGAAGGCTTACGTCTG-3' } \\
\text { R 5'-AGGATCCTTACAACCTCTGC-3' }\end{array}$ & {$[31]$} \\
\hline
\end{tabular}

Other primers were purchased from Qiagen as indicated in Methods 2.2 